Juan Carlos Fuerte-Carrera; Julio César de Jesús Arrias-Áñez; Alba Rosa Pupo-Kairuz

http://dx.doi.org/10.35381/racji.v5i2.1065

\title{
Análisis sobre el peculado y la delincuencia organizada en los procesos de contratación pública emergente
}

\section{Analysis of peculate and organized crime in emerging public procurement processes}

\author{
Juan Carlos Fuerte-Carrera \\ dq.juancfc10@uniandes.edu.ec \\ Universidad Regional Autónoma de Los Andes, Quevedo \\ Ecuador \\ https://orcid.org/0000-0002-8786-9272 \\ Julio César de Jesús Arrias-Áñez \\ uq.julioarrias@uniandes.edu.ec \\ Universidad Regional Autónoma de Los Andes, Quevedo \\ Ecuador \\ https://orcid.org/0000-0001-5259-9359 \\ Alba Rosa Pupo-Kairuz \\ uq.albapupo@uniandes.edu.ec \\ Universidad Regional Autónoma de los Andes, Quevedo \\ Ecuador. \\ https://orcid.org/0000-0002-1719-9250
}

Recibido: 15 de septiembre de 2020

Revisado: 20 de octubre de 2020

Aprobado: 04 de diciembre de 2020

Publicado: 11 de diciembre de 2020 


\title{
RESUMEN
}

El propósito general de la investigación es analizar el proceso de contratación emergente relacionado a la obra Hospital Teodoro Maldonado Carbo del Cantón Guayaquil en Ecuador, la comisión de los delitos de Peculado y Delincuencia Organizada durante la adjudicación directa llevada a cabo, ocasionado por la emergencia sanitaria producto del Covig19. La investigación se desarrolló desde la perspectiva del análisis sintético, se procedió desde una metodología de tipo descriptivo documental con diseño bibliográfico. Se empleó como instrumento de investigación la ficha o guía de análisis documental, lo que contribuyó a extraer las ideas y contrastarlas. Se detectó irregularidades en los procesos de adjudicación y contracción directa. Es necesario una profunda revisión orientadas a futuras reformas legislativas en esta materia, para lograr combatir la corrupción administrativa.

Descriptores: Delincuencia; corrupción; sanción penal. (Palabras Tomadas del Tesauro UNESCO)

\begin{abstract}
The general purpose of the investigation is to analyze the emerging contracting process related to the Teodoro Maldonado Carbo Hospital of the Guayaquil Canton in Ecuador, the commission of the crimes of Embezzlement and Organized Crime during the direct award carried out, caused by the health emergency product of Covig19. The research was developed from the perspective of the synthetic analysis method, proceeded from a documentary descriptive methodology with bibliographic design. The document analysis file or guide was used as a research instrument, which contributed to extract the ideas and contrast them. Irregularities were detected in the adjudication and direct contracting processes. A thorough review is necessary aimed at future legislative reforms in this matter, in order to combat administrative corruption.
\end{abstract}

Descriptors: Delinquency; corruption; criminal sanction. (Words Taken from UNESCO Thesaurus). 
Juan Carlos Fuerte-Carrera; Julio César de Jesús Arrias-Áñez; Alba Rosa Pupo-Kairuz

En los últimos años, el Ecuador ha estado sujeto a diversas políticas públicas ineficaces que han generado altos índices de desempleo, inseguridad y pobreza en detrimento del bienestar común. Los actos de corrupción generados como consecuencia de las irregularidades cometidas en los procesos de selección, contratación y ejecución de obras por parte del Estado desde el año 2000 han provocado entre otras cosas, instrucciones fiscales, detenciones, juicios, obras inconclusas, incautaciones, nuevos procesos licitatorios y de adjudicación directa, así como el cierre de entes públicos.

En este orden de ideas, el Hospital de Especialidades Teodoro Maldonado Carbo de la ciudad de Guayaquil fundado en el año 1970 para brindar atención y servicio médico de manera pública al afiliado se ha caracterizado por su amplia cobertura hospitalaria y tecnología médica para el cuidado de los pacientes. La gerencia de dicho centro de salud ha sido dirigida por diferentes directores que han formulado diversas estrategias comunicacionales como guías de acción en pro de la mejora de la imagen de la institución, sin embargo, el buen prestigio por la gestión realizada ha mermado debido las irregularidades detectada en el protocolo de sus contratos y manejo de recursos desde el año 2015.

Para justificar la mala administración, la gerencia se inventaban emergencias para dar apertura a la adjudicación directa. En este orden, se descubrió una presunta red delictiva que presuntamente venía actuando desde el año 2015 en el Hospital de Especialidades Teodoro Maldonado Carbo de la ciudad de Guayaquil, perteneciente al Instituto Ecuatoriano de Seguridad Social IESS. Los hechos de corrupción afectan a un conjunto de instituciones y además a la colectividad que espera de sus servidores un servicio trasparente y con principio ético, garantizando una buena gestión, sin embargo, como lo plantea, Rodas (2019):

La corrupción es contraria a la ética, inobserva los principios que rigen una vida de respeto para con uno mismo y para con los demás, una suerte de deberes existenciales que nacen de la naturaleza humana. Pero además es contraria al Derecho, no solo porque ciertas conductas estén tipificadas como delitos, sino porque socaba el sistema democrático, burla el Derecho y rompe la armonía social. (p.59) 
Juan Carlos Fuerte-Carrera; Julio César de Jesús Arrias-Áñez; Alba Rosa Pupo-Kairuz

Al respecto, se vislumbró a la luz pública información donde se señalan presuntas irregularidades en el proceso de adjudicación directa por la emergencia sanitaria; por sobreprecios, a través de varios medios de prensa escritos y digitales, en el año 2019 la Comisión Nacional Anticorrupción (CNA) denunció irregularidades cometidas en 2018, relacionadas con contratos con sobreprecio y otorgamiento irregular de adjudicaciones a través de convenios de pago. Tras lo sucedido, la Fiscalía General del Estado ha investigado a funcionarios y demás personas involucradas en este caso de peculado y delincuencia organizada como consecuencia de la socavación de la misión institucional de los servidores públicos que genera un efecto de corrupción, como flagelo que azota la eficiencia de la administración pública que ha evolucionado dentro del entorno ecuatoriano.

En relación a los delitos referenciados, resulta prudente señalar que, según el Artículo 233 de la Constitución de la República del Ecuador indica:

Ninguna servidora ni servidor público estará exento de responsabilidades por los actos realizados en el ejercicio de sus funciones, o por sus omisiones, y serán responsables administrativa, civil y penalmente por el manejo y administración de fondos, bienes o recursos públicos. Las servidoras o servidores públicos y los delegados o representantes a los cuerpos colegiados de las instituciones del Estado, estarán sujetos a las sanciones establecidas por delitos de peculado, cohecho, concusión y enriquecimiento ilícito. La acción para perseguirlos y las penas correspondientes serán imprescriptibles y, en estos casos, los juicios se iniciarán y continuarán incluso en ausencia de las personas acusadas. Estas normas también se aplicarán a quienes participen en estos delitos, aun cuando no tengan las calidades antes señaladas.

El mencionado artículo prescribe claramente los sujetos responsables del abuso de la administración pública. Para ampliar las disposiciones legales se muestra el Código Penal en su artículo 257:

Serán reprimidos con reclusión mayor ordinaria de ocho a doce años, los servidores de los organismos y entidades del sector público y toda persona encargada de un servicio público, que, en beneficio propio o de terceros, hubiere abusado de dineros públicos o privados, de efectos que los representen, piezas, títulos, documentos, bienes muebles o inmuebles que estuvieren en su poder en virtud o razón de su cargo, ya consista el abuso en desfalco, disposición arbitraria o cualquier otra forma semejante. La pena será de reclusión mayor extraordinaria de doce a dieciséis años si la infracción se refiere a fondos destinados a la defensa nacional. 
Se entenderá por malversación la aplicación de fondos a fines distintos de los previstos en el presupuesto respectivo, cuando este hecho implique, además, abuso en provecho personal o de terceros, con fines extraños al servicio público.

Están comprendidos en esta disposición los servidores que manejen fondos del Instituto Ecuatoriano de Seguridad Social o de los bancos estatales y privados. Igualmente están comprendidos los servidores de la Contraloría General y de la Superintendencia de Bancos que hubieren intervenido en fiscalizaciones, auditorías o exámenes especiales anteriores, siempre que los informes emitidos implicaren complicidad o encubrimiento en el delito que se pesquisa.

A priori parece que el marco del ordenamiento jurídico vigente en el Ecuador claramente castiga por el mal uso y el abuso de fondos públicos, continuando en esta tónica, el Asamblea Nacional Código Orgánico Integral Penal de 2014 se tipifica el peculado en su Artículo 278; en el cual se establece como supuesto de hecho que, las o los servidores públicos y las personas que actúen en virtud de una potestad estatal en alguna de las instituciones del Estado, determinadas en la Constitución de la República de Ecuador de 2008, en beneficio propio o de terceros; abusen, se apropien, distraigan o dispongan arbitrariamente de bienes muebles o inmuebles, dineros públicos o privados, efectos que los representen, piezas, títulos o documentos que estén en su poder en virtud o razón de su cargo, serán sancionados con pena privativa de libertad de diez a trece años. De acuerdo a Mañalich (2012;362), los delitos de malversación constituyen delitos especiales (propios). Esto se debe, única y exclusivamente, a que la posición del destinatario de la norma cuyo quebrantamiento es delictivo sólo puede ser ocupada por una persona que exhibe el estatus de funcionario público.

Según el ordenamiento jurídico, mediante el delito de peculado se sanciona al funcionario o servidor público que se apropia o usa, para sí o para otro, caudales o efectos cuya percepción, administración o custodia le están confiadas por razón de su cargo. Para castigar por este delito no solo se exige que el sujeto activo tenga la condición de funcionario público, sino, además, que ostente un vínculo funcional con tales caudales o fondos del Estado.

Se trata de un grupo social con una cierta estructura y con miembros que se organizan para cometer acciones delictivas. A diferencia del delincuente que actúa en solitario, 
Juan Carlos Fuerte-Carrera; Julio César de Jesús Arrias-Áñez; Alba Rosa Pupo-Kairuz

los individuos que forman parte de una banda de delincuencia organizada deben responder a la estructura y cumplir con una determinada función.

Por otra parte, la contratación pública en el Ecuador está basada en la Ley Orgánica del Sistema Nacional de Contratación Pública de 2008, que tiene como objetivo y finalidad garantizar todos los procesos de contratación del país por ende es importante conocer los aspectos esenciales dentro de los procesos de contratación que determina la ley en los concursos para las diversas empresas que deseen postular en la contratación. De acuerdo al Artículo 4: Principios. - Para la aplicación de esta Ley y de los contratos que de ella deriven, se observarán los principios de legalidad, trato justo, igualdad, calidad, vigencia tecnológica, oportunidad, concurrencia, transparencia, publicidad; y, participación nacional.

Según lo detalla la Ley, son objetivos prioritarios del Estado, en materia de contratación pública, los siguientes: Garantizar la calidad del gasto público y su ejecución en concordancia con el Plan Nacional de Desarrollo; garantizar la ejecución plena de los contratos y la aplicación efectiva de las normas contractuales; y la transparencia a fin de evitar la discrecionalidad en la contratación pública; convertir la contratación pública en un elemento dinamizador de la producción nacional; promover la participación de artesanos, profesionales, micro, pequeñas y medianas empresas con ofertas competitivas, en el marco de esta Ley; agilitar, simplificar y adecuar los procesos de adquisición a las distintas necesidades de las políticas públicas y a su ejecución oportuna, entre otros.

Sin embargo, la corrupción sigue campeando en las instituciones públicas, en este sentido Arteño (2017), define el término corrupción:

Desde una perspectiva semántica, proviene del latín rumpere, que significa romper, dividir, quebrar, violar, anular; que a su vez se deriva de corrumpere, cuyo significado es alteración, desunión, descomposición. Corrumpere, entonces, debería significar: "romper con", "romper en unión de", pero en realidad quiere decir "echar a perder, podrir", por lo tanto, la expresión corromper siempre reconoce en líneas generales la presencia de dos partícipes en el acto, que se corresponden principalmente con dos espacios; el corruptor y el corrupto, es decir la fuerza que corrompe y aquella persona sobre el que recae y que en definitiva es lo que se echa a perder, lo que se pudre. (p.41) 
Juan Carlos Fuerte-Carrera; Julio César de Jesús Arrias-Áñez; Alba Rosa Pupo-Kairuz

Las violaciones por parte de algunos funcionarios del Estado, deben llamar a la reflexión, a todos los ciudadanos que conforman la República, en el momento de elegir a nuestros representantes para las diferentes instituciones del estado, promover reformar, nuevas acepciones que combata desde las bases los hechos de corrupción, el peculado y delincuencia organizada, para abordar directamente el delito se comparte el planteamiento de Ramos (2017):

Debe incorporarse una reforma en el que se castiga a quienes hubieren obtenido beneficios mediante el ocultamiento o aprovechamiento de bienes obtenidos mediante la comisión de cualquier delito cometido contra la administración pública. Ha de entenderse que cosas comprende solamente a objetos materiales y se le acompaña una multa que será equivalente al duplo del valor de los bienes ocultados y los beneficios generados, la misma que será determinada en la sentencia condenatoria previo informe pericial. Aunque establecido actualmente en el Código Orgánico, ha de explicitarse y enfatizar en la severidad de aplicación. (p.38)

Continuando con los diferentes hechos en donde se comenten hechos de corrupción se señalar que hacer compras mediante la adjudicación directa sigue siendo un acto justificado, hoy el cumulo de contratos pactados representa un reto para la fiscalización, sin embargo, la Fiscalía y el Comité Anticorrupción en Ecuador ha investigado unos cien números de casos entre ellos "El hospital Teodoro Maldonado Carbo" de la ciudad de Guayaquil, por sobrevaloración de compras públicas realizadas.

En razón de lo argumentado el objetivo de investigación es realizar un análisis jurídico sobre el proceso de contratación emergente realizado en relación a la obra Hospital Teodoro Maldonado Carbo del Cantón Guayaquil en Ecuador con el objeto de determinar la comisión de los delitos de: Peculado y Delincuencia Organizada durante la adjudicación directa llevada a cabo.

\section{METODOLOGÍA}


La investigación se desarrolló desde la perspectiva del análisis sintético, con el apoyo metodológico desde un tipo descriptivo-documental con diseño bibliográfico; lo cual permitió realizar un recorrido centrado en desarrollar un análisis jurídico sobre los delitos de Peculado y Delincuencia Organizada tipificados en el Asamblea Nacional Código Orgánico Integral Penal de Ecuador de 2014, y otras normas de la República. Con la técnica de análisis de contenido, el cual aparece a lo largo de toda la investigación, se realizó el estudio de la información recopilada. Se empleó como instrumento de investigación la ficha o guía de análisis documental, lo que contribuyó a extraer las ideas y contrastarlas.

\section{RESULTADOS}

Los tipos penales de peculado y delincuencia organizada atentan contra la buena marcha de la administración pública en perjuicio de una multiplicidad de víctimas. En este sentido, el término peculado,

En el marco del ordenamiento jurídico vigente en el Ecuador, la Asamblea Nacional Código Orgánico Integral Penal, con data del año 2014, tipifica el Peculado en el artículo 278 de la siguiente manera: Se establece como supuesto de hecho que:

Las o los servidores públicos y las personas que actúen en virtud de una potestad estatal en alguna de las instituciones del Estado, determinadas en la Constitución de la República, en beneficio propio o de terceros; abusen, se apropien, distraigan o dispongan arbitrariamente de bienes muebles o inmuebles, dineros públicos o privados, efectos que los representen, piezas, títulos o documentos que estén en su poder en virtud o razón de su cargo, serán sancionados con pena privativa de libertad de diez a trece años.

Delincuencia organizada, se trata de un grupo social con una cierta estructura y con miembros que se organizan para cometer acciones delictivas. A diferencia del delincuente que actúa en solitario, los individuos que forman parte de una banda de delincuencia organizada deben responder a la estructura y cumplir con una determinada función.

En el Marco Legal del ordenamiento jurídico vigente, la delincuencia organizada de Ecuador está tipificada como un delito en el Asamblea Nacional Código Orgánico 
Juan Carlos Fuerte-Carrera; Julio César de Jesús Arrias-Áñez; Alba Rosa Pupo-Kairuz

Integral Penal (COIP) Quito, 3 de febrero de 2014 en su artículo 369 reza de la siguiente manera:

La persona que mediante acuerdo o concertación forme un grupo estructurado de dos o más personas que, de forma permanente o reiterada, financien de cualquier forma, ejerzan el mando o dirección o planifiquen las actividades de una organización delictiva, con el propósito de cometer uno o más delitos sancionados con pena privativa de libertad de más de cinco años, que tenga como objetivo final la obtención de beneficios económicos u otros de orden material, será sancionada con pena privativa de libertad de siete a diez años. Los demás colaboradores serán sancionados con pena privativa de libertad de cinco a siete años.

En este sentido, la delincuencia organizada implica estructurar una organización criminal den la cual opere un escalafón o niveles de mando donde cada nivel tiene un líder y éste unos subalternos que tienen asignados roles diferentes orientados a la misión criminal y delincuencial de las mafias o carteles nacionales y transnacionales que inclusive tienen una denominación o nombre que impregnan en la ejecución de sus hechos delictivos que representa la asociación de un grupo de personas reclutados por los gestores del talento humano de estas empresas del crimen.

En éste orden de ideas, ambos tipos penales se encuentran adaptados al contexto jurídico de la legislación comparada uno al generar el efecto de corrupción por parte de servidores públicos que fungen como custodios de los bienes del Estado y el otro por generar una multiplicidad de víctimas tal y como lo prevén los instrumentos penales en la materia en países como Venezuela, Colombia, Perú, Chile y Argentina. Ahora bien, en cuanto a las Contrataciones Públicas, el legislador ecuatoriano prevé que la contratación pública en el Ecuador tiene como base legal la Ley Orgánica del Sistema Nacional de Contratación Pública (2008) que tiene como objetivo y finalidad garantizar todos los procesos de contratación del país por ende es importante conocer los aspectos esenciales dentro de los procesos de contratación que determina la ley en los concursos para las diversas empresas que deseen postular en la contratación. Teniendo como ente regulador el Servicio Nacional de Contratación Pública, organismo de derecho público, técnico regulatorio, con personalidad jurídica propia y autonomía administrativa, técnica, operativa, financiera y presupuestaria. Su máximo personero y representante legal será el Director General o la Directora, quien será 
Juan Carlos Fuerte-Carrera; Julio César de Jesús Arrias-Áñez; Alba Rosa Pupo-Kairuz

designado por el Presidente de la República y gozará de fuero de Corte Nacional de Justicia, en las mismas condiciones que un ministro de Estado.

Dentro de este contexto, como consecuencia de la emergencia sanitaria el Estado de Excepción permite la aplicación de las Adjudicaciones Directas, suprimiendo los proceso licitatorios más engorrosos en pro de adquirir los insumos y equipos médicos necesarios para combatir el coronavirus junto a la construcción de hospitales necesarios para cubrir las necesidades de salud de la población afectada como lo fue especialmente en su momento la ciudad de Guayaquil, primer epicentro del Covid 19 en Latinoamérica. Cruz, M., Santos, E., Cervantes, M., \& Juárez, M. (2020).

Todas estas irregularidades detectadas y que salieron a la opinión pública de manera escandalosa produce el efecto de la corrupción y hecho punible. Al respecto, Schünemann. (2018), lo define como:

la definición del hecho punible mediante la infracción de la norma prohibitiva típica resulta circular, ya que no se puede indicar ningún criterio mediante el cual diferenciar las normas prohibitivas penales de las otras miles y miles de normas prohibitivas. (p.4)

En este sentido, la corrupción pública presente a través de tráfico de influencias, conflicto de intereses, desviación arbitraria de fondos públicos, prevaricato, estafa, extorsión, reclamaciones fraudulentas, estados financieros erróneos o maquillados, conspiración, concusión, cohecho, entre otras infracciones denunciadas últimamente, son conductas humanas lesivas que atañe a todos y afectan a nuestra sociedad; por cuanto pone en tela de duda la integridad de la gestión pública. En tal sentido, De La Torre (2017) realiza el siguiente planteamiento:

Los perjuicios económicos que devienen de los delitos de corrupción, lavado de activos, extorsión, secuestro, trata de personas, narcotráfico, defraudación tributaria, entre otros, son enormes afectando a todos los Estados y dentro de ellos a la sociedad en sí y por tanto a las empresas, es decir en general a todos quienes conformamos las naciones, por lo que se asevera que este fenómeno está presente en todos los países y en todos los niveles de la sociedad. (p.15)

El tema es de actualidad tanto a nivel nacional como internacional si se tiene en cuenta lo que representa en este orden la continua rotación de directores o gerentes y 
Juan Carlos Fuerte-Carrera; Julio César de Jesús Arrias-Áñez; Alba Rosa Pupo-Kairuz personal de confianza de los mismos, provocada por una ola de corrupción la cual no es nueva, ni tiene relación exclusiva con la crisis sanitaria que vive el país y el mundo entero por pandemia provocada por el virus del covid-19 o Coronavirus, se trata de un proceso de propagación de contrataciones públicas para adquisición de insumos médicos y otros utensilios orientados a combatir dicha enfermedad por parte de varios centros de salud.

\section{DISCUSIÓN}

El presente trabajo investigación, se justifica desde un punto de vista social; por cuanto, permitió dar a conocer la normativa existente en materia penal y administrativa relativa a la inobservancia de las leyes al momento de realizar contrataciones de emergencia en los hospitales por la crisis sanitaria del covid 19 y las sanciones penales que esto acarrea. Desde un punto de vista práctico servirá para concientizar a los actores involucrados en estas situaciones conflictivas y a conocer mecanismos de acción y mejora a las mismas, desde un punto de vista teórico en virtud de que se desarrolla teoría y se fundamenta realizando un análisis jurídico sobre la normativa legal vigente en la materia.

Esta investigación permitió detectar que la crisis sanitaria suscitada por la propagación del virus del covid 19 hasta el país por efecto de la pandemia, generó el decreto del Estado de Emergencia Nacional por calamidad pública que originó la apertura de contrataciones públicas bajo la modalidad de adjudicaciones directas para justificar la adquisición de equipos e insumos necesarios con el objeto de combatir los graves efectos que deja el coronavirus.

En este escenario, el Instituto ecuatoriano de Seguridad Social (IESS) y varios Hospitales adscritos a éste ente gubernamental, iniciaron los procesos correspondientes en los cuales hubo una serie de irregularidades en virtud del sobreprecio de los insumos en detrimento del presupuesto de salud de todos los ecuatorianos. Así las cosas, se favoreció a ciertos empresarios de manera ilícita y no se cumplió con el cronograma de ejecución previsto en la oferta de las empresas ganadoras tal y como ocurrió con la obra de construcción del Hospital Teodoro Maldonado Carbo de Pedernales en la Provincia de Manabi, trayendo como 
Juan Carlos Fuerte-Carrera; Julio César de Jesús Arrias-Áñez; Alba Rosa Pupo-Kairuz

consecuencia un efecto lesivo de corrupción derivado de todo éste entramado de delincuencia organizada.

La investigación resultó importante por cuanto se detectaron las denuncias e investigaciones que prosiguen el sistema penal ecuatoriano a través de la Fiscalía ha demostrado que en un expediente se menciona una afectación de USD 3,1 millones entre las cuales existen también compras de insumos y de medicamentos concretados por USD 5,8 millones, pero los agentes que analizaron las licitaciones calculan que el precio real debió ser de USD 2,7 millones; es decir, en este caso se investiga un posible sobreprecio del $114,8 \%$ ya que los funcionarios del Hospital se inventaban supuestos estados de "emergencia" para adjudicar de forma directa a contratistas determinados y mediante esta forma, evadían los controles de contratación pública, con la investigación se ponen en evidencias actos de corrupción de este centro hospitalario que van en detrimento del Estado y de la ciudadanía en general.

\section{CONCLUSIONES}

En el presente trabajo de investigación se llegó a las siguientes conclusiones:

Desde la fundamentación teórica sobre la comisión de los delitos de peculado y la delincuencia organizada en la crisis sanitaria, se concluye que son tipos penales que representan una acción dolosa, lesiva y gravosa que socava el bien jurídico tutelado por el Estado como lo es la buena marcha de la eficiencia de la administración pública en perjuicio del orden público y del principio rector del buen vivir, causando un desorden social e inseguridad jurídica al concretarse el desvío de los fondos públicos por la orquestación de estructuras criminales que tienen por objeto apodarse del patrimonio nacional.

Desde el diagnóstico del estado actual sobre la comisión de los delitos de peculado y la delincuencia organizada en la crisis sanitaria durante la emergencia sanitaria ocasionada por el COVD 19, se concluye que existen varias investigaciones iniciadas por el titular de la acción que se encuentran en fase de investigación previa y etapa de instrucción, por la adquisición de insumos médicos con sobreprecios a través de contratos con irregularidades, que ha ocasionado una ola procedimientos judiciales a nivel nacional por supuesta corrupción en hospitales y gobiernos seccionales. Siendo 
Juan Carlos Fuerte-Carrera; Julio César de Jesús Arrias-Áñez; Alba Rosa Pupo-Kairuz

una de las más emblemáticas la relacionada la construcción del Hospital Teodoro Maldonado Carbo de Pedernales en la Provincia de Manabi.

Desde el desarrollo del análisis jurídico, se concluye que existe una alta incidencia del delito de peculado en el ecuador como parte de un entramado vinculado a la delincuencia organizada que se ha incrementado como consecuencia del desarrollo de la pandemia y crisis sanitaria derivada del Covid 19 que ha generado la transgresión de normas jurídicas previstas en los procesos de adjudicaciones directas que han afectado contrataciones públicas importantes como el Hospital Teodoro Maldonado Carbo, representando éste flagelo la socavación de la buena marcha del debido proceso que debe regir en estos procedimientos previstos en nuestra legislación, coyuntura que resulta alarmante por cuanto opera la transgresión del principio de legalidad en pro de la impunidad en detrimento de la seguridad jurídica y el buen vivir configurándose la transgresión del principio de proporcionalidad también por cuanto las penas que imponen estos tipos penales como sanciones resultan benignas razón por la cual se amerita una profunda revisión orientadas a futuras reformas legislativas.

\section{FINANCIAMIENTO}

No monetario.

\section{AGRADECIMIENTO}

A la Universidad Regional Autónoma de Los Andes, Quevedo; por motivar el desarrollo de la Investigación. 


\section{REFERENCIAS CONSULTADAS}

Arteño, R. (2017) Derecho Constitucional en Ecuador y Aspectos Sobre la Corrupción desde lo Penal. [Constitutional Law in Ecuador and Semblances on the Corruption from Penal's view] Revista Chakiñan, 2,35-46. Recuperado en: http://chakinan.unach.edu.ec/index.

Asamblea Nacional (2014). Codigo Organico Integral Penal. [Comprehensive Criminal Code]. Registro Oficial № 180. Recuperado de https://url2.cl/53c6h

Asamblea Nacional Constituyente de la República del Ecuador, (2008). Constitución de la República del Ecuador. Montecristi. Registro Oficial 449 de 20-oct-2008. Recuperado de https://n9.cl/sia

Cruz, M., Santos, E., Cervantes, M., \& Juárez, M. (2020) COVID-19, a worldwide public health emergency. Rev Clin Esp 2020; 20. Rev Asoc Esp Med Trab.29,(1) ,181.Recuperado en: http://scielo.isciii.es/pdf/medtra/v29n1/1132-6255-medtra29-01-10.pdf

De La Torre, C. (2017). Relación existente entre paraísos fiscales, lavado de activos y defraudación tributaria. Un análisis desde la normativa de Ecuador. [Relationship between tax havens, money laundering and tax fraud. An analysis from Ecuador's regulations]. Revista de la Facultad de Derecho, 43,13-36. ISSN 0797-8316. http://dx.doi.org/10.22187/rfd2017n2a2

Gobierno de la República del Ecuador (2008). Ley Orgánica del Sistema Nacional de Contratación Pública. [National Government Procurement System Organic Law] (registro Oficial Suplemento 395 del 04 de agosto de 2008). Recuperado en: www.lexis.com.ec.

Mañalich, J. (2012). La malversación de caudales públicos y el fraude al fisco como delitos especiales. [Embezzlement of public funds and tax fraud as special crimes] Revista Polít. crim. 7(14),357-377. (Santiago). http://dx.doi.org/10.4067/S0718-33992012000200004.

Ramos, R. (2017) Derecho Constitucional en Ecuador y aspectos sobre la corrupción desde lo penal. [Constitutional law in Ecuador and Semblances on the corruption fro penal's view]. Revista Chakiñan de Ciencias Sociales y Humanidades, 2. ISSN 2550-6722.

Roda, Ivan-Saquicela(2019). La persecución penal de los delitos de corrupción en las altas esferas de la administración pública desde una perspectiva con base ética. [Criminal prosecution of corruption offences in the upper echelons of public administration from an ethical perspective] Revista Científica de Ciencias Jurídicas Criminología y Seguridad, 26,65-69 ISSN:2661-6855. 
lustitia Socialis. Revista Arbitrada de Ciencias Jurídicas.

Año V. Vol. V. №2. Edición Especial. 2020-II

Hecho el depósito de Ley: FA2016000064

ISSN: 2542-3371

FUNDACIÓN KOINONIA (F.K). Santa Ana de Coro, Venezuela

Juan Carlos Fuerte-Carrera; Julio César de Jesús Arrias-Áñez; Alba Rosa Pupo-Kairuz

Schünemann, B. (2018). Dominio sobre la vulnerabilidad del bien jurídico o infracción del deber en los delitos especiales. [Control over Vulnerability of Interest or Breach of Duty in Special Delicts]. Pontificia Universidad Católica del Perú. DOI: https://doi.org/10.18800/derechopucp.201802.003.

(C2020 por los autores. Este artículo es de acceso abierto y distribuido según los términos y condiciones de la licencia Creative Commons Atribución-NoComercial-Compartirlgual 4.0 Internacional (CC BY-NC-SA 4.0)

(https://creativecommons.org/licenses/by-nc-sa/4.0/). 